\title{
[E] EDUMASPUL
}

Vol. 5 - No. 1, year (2021), page 410 - 416

| ISSN 2548-8201 (Print)| 2580-0469) (Online)|

\section{PENGARUH GAYA MENGAJAR RESIPROKAL DAN GAYA MENGAJAR LATIHAN DENGAN KEBUGARAN JASMANI TERHADAP HASIL BELAJAR PASSING SEPAKBOLA}

YOGHA ZULVIA ISKANDAR

(PGPUD/STIT Rakeyan Santang, Kabupaten Karawang).

* Corresponding Author. E-mail: ${ }^{1}$ yogha@ rakeyansantang.ac.id

Receive: 05/03/2021

Accepted: 07/03/2021

Published: 23/03/2021

\begin{abstract}
Abstrak
Penelitian ini bertujuan untuk mengetahui pengaruh gayamengajar dan kebugaran jasmani terhadap hasil belajar passing sepak bola. Penelitian ini menggunakan metode eksperimen dengan desain by level $2 \times 2$. Penggambilan sampel menggunakan teknik purposive sampling, dimana penetuan sampel dengan pertimbangan tertentu. Jumlah sampel sebanyak 40 orang siswa yang dibagi menjadi 4 kelompok. Teknik analisis data menggunakan analysis of variance (ANAVA) dua jalur kemudian dilanjutkan dengan Uji Tukey. Hasil penelitian secara keseluruhan didapatkan bahwa (1). Terdapat perbedaan signifikan dari hasil belajar dalam permainan sepak bola antara gaya mengajar resiprokal dan latihan, yakni; F-hitung gaya mengajar $=8,24$, lebih besar dari pada $F$ tabel, yaitu 4,11. (2). Terdapat interaksi dimana gaya mengajar dan kebugaran jasmani memberikan pengaruh terhadap hasil passing sepak bola secara bersama-sama, dimana F-hitung $=56,39>$ F-tabel $=4,11$. (3). Terdapat perbedaan signifikan antara gaya mengajar resiprokal dan latihan pada kebugaran jasmani tinggi, hasil penelitian menunjukkan bahwa gaya mengajar resiprokal lebih baik dari pada gaya mengajar latihan, batas uji Tukey (w) yaitu 1,59. (4). Terdapat perbedaan signifikan antara gaya mengajar latihan dan resiprokal pada kebugaran jasmani rendah, hasil penelitian menunjukkan bahwa gaya mengajar latihan lebih baik dari pada gaya mengajar resiprokal, batas uji Tukey (w) yaitu 1,01.
\end{abstract}

Kata Kunci: Gaya Mengajar, KebugaranJasmani, PassingSepakbola.

\section{Instructions for Preparing Manuscript for Jurnal Edumaspul (2019 Template Version) $\leftarrow 13$ TNR Bold Italic 12 Words}

This study aims to determine the effect of teaching style and physical fitness to the learning outcomes of passing football. This research used experimental method to the design by the level of $2 \times 2$. Sampling using purposive sampling, where the determination of a sample with a certain considerations. Total sample of 40 students who were divided into 4 groups. Data were analyzed using analysis of variance (ANOVA) followed by two lines Tukey test. The results showed that the overall study (1). There are significant differences of learning outcomes in a football game between reciprocal teaching style and practice style, that is; F- 
arithmetic teaching style $=8,24$, greater than the $F$ table, that is 4.11 . (2). There is an interaction where teaching style and physical fitness to give effect to the results of passing football, where the F-count $=56,39>$ F-table $=4.11$. (3). There are significant differences between reciprocal teaching style and practice teaching style at a highphysical fitness, the results showed that the reciprocal teaching style is better than the practice teaching style, limit Tukey test $(w)$ is 1.59. (4). There are significant differences between the practice teaching styles and reciprocal teaching style at a low physical fitness, the results showed that the teaching style of practice is better than reciprocal teaching style, Tukey test limit $(w)$ is 1.01 .

\section{Keyword: Teaching Style, Physical Fitness, Passing Football.}

\section{Pendahuluan}

Pendidikan jasmani sebagai komponen Pendidikan secara keseluruhan telah disadari oleh banyak kalangan. Namun, dalam pelaksanaannya pengajaran pendidikan jasmani berjalan belum efektif seperti yang diharapkan. Pembelajaran pendidikan jasmani cenderung tradisional. Pengertian pendidikan jasmani sering dikaburkan dengan konsep lain. Konsep tersebut menyamakan pendidikan jasmani dengan setiap usaha atau kegiatan yang mengarah pada pengembangan organorgan tubuh manusia, kesegaran jasmani, kegiatan fisik, dan pengembangan keterampilan. Pengertian itu memberikan pandangan yang sempit dan menyesatkan arti pendidikan jasmani yang sebenarnya. Walaupun memang benar aktivitas fisik itu mempunyai tujuan tertentu, namun karena tidak dikaitkan dengan tujuan pendidikan, maka kegiatan itu tidak mengandung unsur-unsur pedagogik. Pendidikan jasmani bukan hanya merupakan aktivitas pengembangan fisik secara terisolasi, akan tetapi harus berada dalam konteks pendidikan secara umum. Sudah tentu proses tersebut dilakukan dengan sadar dan melibatkan interaksi sistematik antar pelakunya untuk mencapai tujuan yang telah ditetapkan. Dengan pendidikan jasmani siswa akan memperoleh berbagai ungkapan yang erat kaitannya dengan kesan pribadi yang menyenangkan serta berbagai ungkapan yang kreatif, inovatif, terampil, memiliki kebugaran jasmani, kebiasaan hidup sehat dan memiliki pengetahuan serta pemahaman terhadap gerak manusia. Kurikulum pendidikan jasmani terdiri dari bermacam-macam aktivitas yang salah satunya adalah permainan sepak bola. Sepak bola merupakan permainan beregu, masingmasing regu terdiri dari sebelas pemain, dan salah satunya penjaga gawang. Permainan ini hampir seluruhnya dimainkan dengan menggunakan tungkai, kecuali penjaga gawang yang dibolehkan menggunakan lengannya di daerah tendangan hukumannya. Salah satu karakteristik teknik dasar dalam permainan sepak bola yang paling dominan dilakukan adalah passing atau menendang bola. Untuk membuat hasil tendangan yang baik, maka perlu menguasai prinsip-prinsip dalam menendang bola. Passing merupakan salah satu dari beberapa teknik dasar yang harus dikuasai dalam permainan sepak bola. Passing dalam sepak bola merupakan teknik dasar yang paling sering dilakukan oleh pemain. Kegunaan dari passing ini yaitu untuk mengoper atau memindahkan bola dari satu pemain ke pemain yang lain untuk mengamankan bola dari lawan. Passing membutuhkan banyak teknik yang sangat penting agar dapat tetap menguasai bola. Peningkatan hasil belajar passing sangat 
dibutuhkan peran guru yang memberikan sebuah stimulus terhadap siswa melalui gaya mengajar yang diterapkan oleh guru pendidikan jasmani, karena gaya mengajar sangat mempengaruhi hasil belajar siswa. Sehingga jika seorang guru pendidikan jasmani kurang menguasai gaya mengajar atau model pembelajaran akan membuat siswa semakin jenuh dalam mengikuti pembelajaran pendidikan jasmani. Salah satu kenyataan dalam penyajian pembelajaran passing sepak bola dilapangan adalah pembelajaran yang dilakukan monoton, tidak diberikan pemahaman kognitif pada siswa dimana siswa harus memahami apa, bagaimana, dan mengapa passing dilakukan, kemudian gaya mengajar yang tidak membangkitkan motivasi belajar siswa serta kemampuan gerak siswa yang terbatas. Dalam hal ini seorang guru harus bisa menciptakan suasana belajar yang menyenangkan sehingga siswa bersemangat untuk mengikuti proses pembelajaran. Banyaknya macam gaya mengajar, maka seorang guru harus cermat dan tepat dalam memilihnya agar tujuan pembelajaran yang telah ditetapkan dapat dicapai secara optimal. Karena pembelajaran yang dilakukan sebelumnya terlihat kurang menarik minat dan semangat yang menyebabkan hasil belajar siswa menurun. Demikian juga dalam proses belajar mengajar, bila guru dalam proses belajar mengajar tidak menggunakan variasi atau gaya mengajar lainnya, maka akan membosankan siswa, perhatian siswa berkurang dan berakibat tujuan belajar tidak tercapai. Untuk mencapai tujuan pembelajaran tersebut seorang guru dapat menerapkan salah satu gaya mengajar atau mengkombinasikan dari beberapa gaya mengajar. Pemilihan gaya mengajar yang tepat, merupakan salah satu yang tidak dapat dilupakan atau diabaikan dalam proses rancangan pembelajaran pendidikan jasmani karena hal itu banyak berpengaruh terhadap faktor kognitif maupun faktor psikomotor. Gaya mengajar yang akan dilakukan adalah gaya mengajar resiprokal dan gaya mengajar latihan.

\section{Metode}

Penelitian dilakukan dengan menggunakan metode eksperimen. Sugiyono (2010:12) Metode eksperimen adalah metode yang digunakan untuk mencari pengaruh treatment (perlakuan) tertentu. Dalam penelitian ini adalah dengan membandingkan dua gaya mengajar yang berbeda, yaitu gaya mengajar resiprokal dan gaya mengajar latihan dengan variabel atribut kebugaran siswa yang terdiri dari kebugaran tinggi dan kebugaran rendah.

Desain penelitian yang digunakan adalah by level $2 \times 2$ dengan terdapat tiga variabel penelitian, yaitu satu variabel terikat dan dua variabel bebas. Sebagai variabel terikat (dependent variable) adalah hasil belajar passing sepak bola dan dua variabel bebas (independent variable) adalah gaya mengajar dan kebugaran jasmani siswa. Variabel perlakuan pembelajaran dibedakan menjadi dua, yaitu gaya mengajar resiprokal $\left(A_{1}\right)$ dan gaya mengajar latihan $\left(A_{2}\right)$. Variabel yang mempengaruhi yaitu kebugaran jasmani tinggi $\left(\mathrm{B}_{1}\right)$ dan kebugaran jasmani rendah $\left(\mathrm{B}_{2}\right)$.

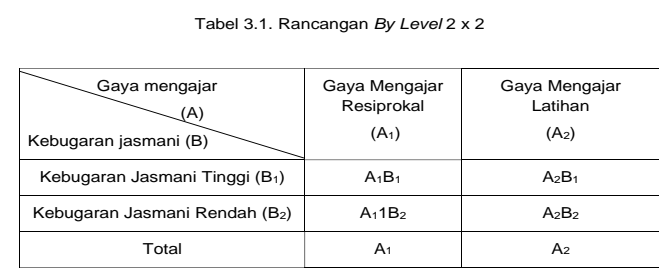

Populasi target yang dilibatkandalampenelitianiniadalahseluruh siswaKelas X SMA Negeri 1 Tegalwaru. Sedangkanpopulasiterjangkaudalampenelit ianiniadalahsiswaputra Kelas $\mathrm{X}$ sebanyak 148 orang.

Pengambilan sampel dilakukan dengan teknik simple random sampling, yaitu menetapkan secara acak dari jumlah populasi terjangkau sebanyak 74 siswa 
dengan cara mengacak siswa dengan memberikan undian kertas yang di gulung. Siswa yang mendapatkan tulisan "Ya" akan menjadi kerangka sampel dalam penelitian ini. Kerangka sampel 74 siswa ini kemudian diundi untuk di masukkan ke dalam dua kelompok perlakuan, sehingga diperoleh kelompok gaya mengajar resiprokal dan gaya mengajar latihan.

Untuk menentukan kategori tinggi dan rendahnya kebugaranjasmanipada masingmasing kelompok, dilakukan tes kepada anggota kelompok. Hasil tes dari masingmasing anggota kelompok disusun menurut skor nilai yang diperoleh yaitu mulai dari skor tertinggi sampai skor yang paling rendah.

Dengan menyeleksi $27 \%$ jumlah data skor tertinggi dan $27 \%$ skor terendah. Selanjutnya, $27 \%$ dari jumlah skor data tertinggi digolongkan dalam kelompok yang memiliki kebugaran jasmani tinggi $\left(B_{1}\right)$, sedangkan $27 \%$ dari jumlah skor terendah digolongkan dalam kelompok yang memiliki kebugaran jasmani rendah $\left(B_{2}\right)$ dari masing-masing kelompok.

Berdasarkan perhitungan tersebut didapatkan $27 \%$ dari siswa yang memiliki skor tinggi adalah $27 \% \times 74=19,98$ dibulatkan menjadi 20 orang siswa. Dan pada siswa yang memiliki skor rendah adalah $27 \% \times 74=19,98$ dibulatkan menjadi 20 orang siswa. Sehingga masingmasing kelompok berjumlah 10 orang siswa. Dengan demikian hasil pengambilan sampel (1) kelompok pertama adalah kelompok siswa yang diberikan dengan gaya mengajar resiprokal yang memiliki kebugaran jasmani tinggi $\left(A_{1} B_{1}\right)$, kelompok kedua adalah kelompok siswa yang di belajarkan dengan gaya mengajar yang memiliki kebugaran jasmani rendah $\left(A_{1} B_{2}\right)$, (3) kelompok ketiga adalah kelompok siswa yang di belajarkan dengan gaya mengajar latihan yang memiliki kebugaran jasmani tinggi $\left(A_{2} B_{1}\right)$, dan (4) kelompok keempat adalah kelompok siswa yang dibelajarkan dengan gaya mengajar

\begin{tabular}{|c|c|c|c|}
\hline Kebugaran Jasmani(B) & $\begin{array}{c}\text { Gaya } \\
\text { Mengajar } \\
\text { Resiprokal } \\
\left(\mathbf{A}_{1}\right)\end{array}$ & $\begin{array}{c}\text { Gaya } \\
\text { Mengajar } \\
\text { Latihan } \\
\left(\mathbf{A}_{2}\right)\end{array}$ & Jumlah \\
\hline $\begin{array}{l}\text { Kebugaran Jasmani Tinggi } \\
\qquad\left(B_{1}\right)\end{array}$ & 10 & 10 & 20 \\
\hline $\begin{array}{l}\text { Kebugaran Jasmani } \\
\text { Rendah }\left(\mathrm{B}_{2}\right)\end{array}$ & 10 & 10 & 20 \\
\hline Total & 20 & 20 & 40 \\
\hline
\end{tabular}

memiliki kebugaran jasmani $\left(A_{2} B_{2}\right)$. Matrik pengelompok sampel eksperimen dapat dilihat pada tabel di bawah ini.

Sesuai dengan rancangan penelitian, maka terdapat dua macam data yang harus dikumpulkan,yaitu: (1) data tentang hasil belajar passing sepak bola, dan (2) data tentang kebugaran jasmani siswa.

Untuk memperoleh data tentang hasil belajar passing sepakbola maupun data kebugaran jasmani siswa maka dilakukan tes dan pengukuran. Untuk mengukur hasil belajar passing sepak bola dan kebugaran jasmani siswa maka dibuatkan instrument penelitian.

\begin{tabular}{|c|c|c|c|c|c|c|c|c|}
\hline $\begin{array}{c}\text { Kebugaran } \\
\text { Jasmani }\end{array}$ & $\begin{array}{l}\text { Gaya } \\
\text { Belajar }\end{array}$ & $\mathbf{n}$ & $\bar{X}$ & $s^{2}$ & $s$ & $X_{\max }$ & $X_{\min }$ & Rentang \\
\hline \multirow{2}{*}{$\begin{array}{l}\text { Kebugaran } \\
\text { Jasmani } \\
\text { Tinggi (B1) }\end{array}$} & $\begin{array}{l}\text { Resiprokal } \\
\text { (A1) }\end{array}$ & 10 & 18 & 1,789 & 1,337 & 20 & 16 & 4 \\
\hline & $\begin{array}{l}\text { Latihan } \\
\text { (A2) }\end{array}$ & 10 & 16 & 2,4 & 1,549 & 18 & 14 & 4 \\
\hline \multirow{2}{*}{$\begin{array}{l}\text { Kebugaran } \\
\text { Jasmani } \\
\text { Rendah (B2) }\end{array}$} & $\begin{array}{l}\text { Resiprokal } \\
\text { (A1) }\end{array}$ & 10 & 14 & 2,178 & 1,476 & 16 & 12 & 4 \\
\hline & $\begin{array}{l}\text { Latihan } \\
\text { (A2) }\end{array}$ & 10 & 18 & 1,833 & 1,354 & 20 & 16 & 4 \\
\hline \multirow{2}{*}{ Keseluruhan } & $\begin{array}{l}\text { Resiprokal } \\
\text { (A1) }\end{array}$ & 20 & 16 & 7,208 & 2,685 & 20 & 12 & 8 \\
\hline & $\begin{array}{l}\text { Latihan } \\
\text { (A2) }\end{array}$ & 20 & 17 & 3,397 & 1,843 & 20 & 14 & 6 \\
\hline
\end{tabular}

Perlakuan dalam penelitian ini adalah menggunakan gaya mengajar sebagai variabel bebas yaitu gaya mengajar resiprokal dan latihan, serta kebugaran jasmani sebagai variabel bebas moderator. Peneliti mengajarkan materi passing permainan sepak bola pada masing-masing kelas perlakuan. Kondisi yang di ciptakan untuk kedua kelompok perlakuan ini diusahakan sama, kecuali menggunakan gaya mengajar. Perlakuan yang sama antara lain standar kompetensi, materi, waktu (jumlah tatap muka), dan semester. 


\section{Hasil dan Pembahasan}

Deskripsi data bertujuan untuk memberikan informasi mengenaikara kteristik data. Ada banyak statistik yang masuk kedalam kategori statistika deskriptif. Namun, pada bagian ini hanya akan disajikan statistik yang dianggap perlu saja. Adapun statistik yang dimaksuddisajikantabel 4.1 di bawahini :

Distribusifrekuensihasilbelajar passing sepak bola kelompokgayamengajarresiprokalsecarake seluruhan

\begin{tabular}{|c|cc|cc|c|c|}
\hline Kelas & Interval & Batas Kelas & $\begin{array}{c}\text { Frekuensi } \\
\text { absolut }\end{array}$ & $\begin{array}{c}\text { Frekuensi } \\
\text { relatif }(\%)\end{array}$ \\
\hline 1 & 12 & -13 & 11.5 & -13.5 & 5 & 25 \\
2 & 14 & -15 & 13.5 & -15.5 & 3 & 15 \\
3 & 16 & -17 & 15.5 & -17.5 & 5 & 25 \\
4 & 18 & -19 & 17.5 & -19.5 & 5 & 25 \\
5 & 20 & -21 & 19.5 & -21.5 & 2 & 10 \\
\hline \multicolumn{3}{|c|}{ Jumlah } & & & 18 & 100 \\
\hline
\end{tabular}

Agar deskripsimenjadilebihjelas, disajikan histogram dari data pada tabel 4.2 pada gambar 4.1 di bawahini.

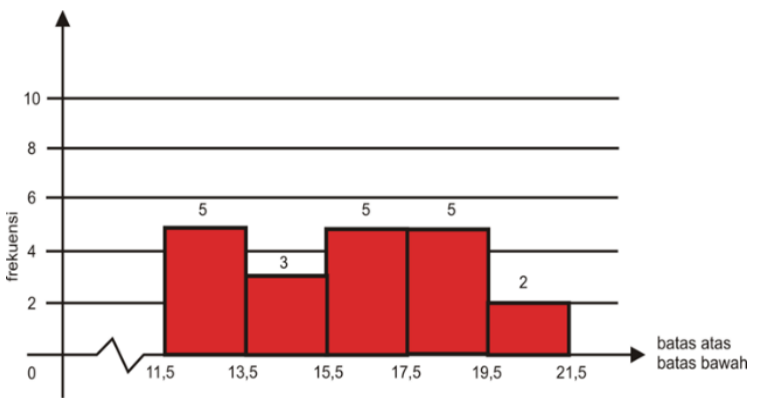

Distribusifrekuensihasilbelajar passing sepak bola, kelompokgayamengajarlatihansecarakesel uruhan

\begin{tabular}{|c|c|c|c|c|}
\hline Kelas & Interval & Batas Kelas & $\begin{array}{c}\text { Frekuensi } \\
\text { absolut }\end{array}$ & $\begin{array}{l}\text { Frekuensi } \\
\text { relatifi }(\%)\end{array}$ \\
\hline 1 & $14 \cdot 15$ & $13.5-15.5$ & 3 & 15.0 \\
\hline 2 & $16 \cdot 17$ & $15.5 \cdot 17.5$ & 6 & 30.0 \\
\hline 3 & $18 \cdot 19$ & $17.5-19.5$ & 8 & 40.0 \\
\hline 4 & $20 \cdot 21$ & $19.5 \cdot 21.5$ & 3 & 15.0 \\
\hline \multicolumn{2}{|c|}{ Jumlah } & & 20 & 100 \\
\hline
\end{tabular}

Agar deskripsimenjadilebihjelas, disajikan histogram dari data pada tabel 4.2 pada gambar 4.2 di bawahini.

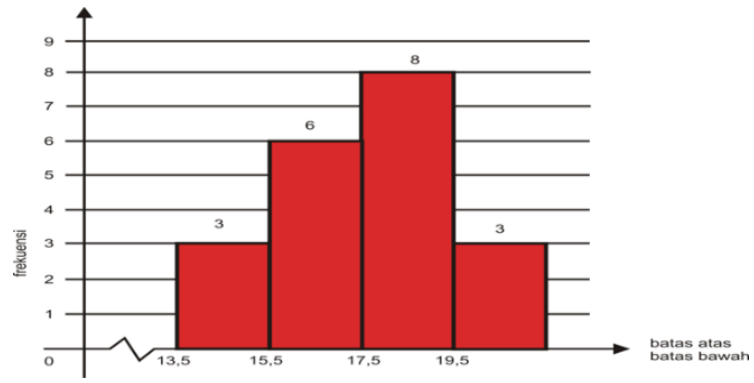

Distribusifrekuensihasilbelajar passing sepak bola, kelompok gaya mengajar resiprokal dengan kebugaran jasmanit inggi.

\section{Simpulan}

Dari hasil penelitian hipotesis dan pembahasan penelitian maka dapatdiambilkesimpulanbahwa:

1. Terdapat perbedaan hasil belajar passing sepak bola antara gaya mengajar resiprokal dan gaya mengajar latihan

2. Terdapat interaksi antara gaya mengajar dengan kebugaran jasmani terhadap hasil belajar passing sepakbola.

3. Hasil belajar passing dalam permainan sepakbola siswa dengan kebugaran jasmani tinggi yang diajar dengan gaya mengajar resiprokal memberikan hasil lebih baik daripada gaya mengajar latihan.

4. Hasil belajar passing dalam permainan sepakbola siswa dengan kebugaran jasmani rendah yang diajar dengan gaya mengajar latihan memberikan hasil lebih baik daripada gaya mengajar resiprokal.

\section{DaftarPustaka}

Penyusunan Daftar Pustaka yang mengikuti teknik yang standar harus dilakukan secara baku dan konsisten. Untuk menjaga konsistensi cara 
pengacuan, pengutipan dan daftar pustaka sebaiknya menggunakan aplikasi Reference Manager, seperti Zotero, Mendeley, atau aplikasi berbayar yang lain. Ditulis dalam spasi tunggal, antardaftar pustaka diberi jarak 1 spasi. Sebagian contoh cara penulisan referensi/ acuan di dalam Daftar Pustaka, diberikan berikut.

[1] Departemen Pendidikan Nasional Pusat Pengembangan Kualitas Jasmani, Tes Kebugaran Jasmani Indonesia Untuk Anak Umur 13-15 Tahun Jakarta: 2003

[2] D.Sukmara. Implementasi Program Life Skill. Bandung: Mughni Sejahtera, 2005.

[3] Faruq, Muhyi M. Meningkatkan Kebugaran Tubuh Melalui Permainan \& Olahraga Sepak Bola, Jakarta:Grasindo, 2008.

[4] Husdarta. Rosdiani, Dini. Model Pembelajaran Langsung dalam Pendidikan Jasmani dan Kesehatan. Bandung: Alfabeta, 2013.

[5] Husdarta. Manajemem Pendidikan Jasmani. Bandung : Alfabeta, 2001.

[6] Luke Kelly.E. Developing the Physical Education Curriculum. United States: Human Kinetics, 2004.

[7] Luxbcher, Joseph A. Sepakbola. Jakarta: Rajagafindo persada, 2012

[8] Majid, Abdul. Strategi Pembelajaran. Bandung: Rosda, 2014.

[9] Midkar. Hidup sehat: Nilai Inti Berolahraga. Departemen Pendidikan Nasional Jenderal Pendidikan Tinggi Direktorat Ketenagaan: 2006.

[10] Mielke, Danny. Dasar-Dasar Sepak Bola. Bandung: Pakar Raya, 2007.
[11] Mosston, Muska. Ashworth Sa ra. PengajaranPendidikanJasmani, (Edisi Online Pertama):2008.

[12] Mosston, Muska. Ashworth Sara, Teaching Physical Education. New York: Macmillan College Publishing Company, 2008.

[13] Nurhasan. Tes dan Pengukuran Keolahragaan. Bandung: UPI, 2014.

[14] Rahayu, Trisna Ega. Strategi Pembelajaran Pendidikan Jasmani. Bandung: Alfabeta, 2013

[15] Rohim, Abdul. Bermain sepak bola. Semarang:Aneka ilmu, 2008.

[16] Ro"sch Dieter, Hodgson Roy, Peterson Lars, Graf-Baumann Toni, Junge Astrid, Chomiak Jiri, Dvorak Jiri. Assessment and Evaluation of Football Performanc. American Journal of Sports Medicine :Vol. 28, No. 5, 2000.

[17] Rusman. Model-Model Pembelajaran. Jakarta: Rajawali Pers, 2011

[18] Sucipto, dkk. Sepak Bola. Bandung: Bandung: Departemen Pendidikan Nasional, 2000.

[19] Sackett, Paul R. Mavor, Anne S. Assessing fitness for military enlistment : physical, medical, and mental health standards. (National Research Council (U.S.): Committee on the Youth Population and Military Recruitment, 2006.

[20] Sugiyono. Metode Penelitian PendidikanPendekatan Kuantitatif, Kualitatif, R\&D. Bandung: Alphabeta,2010

[21] Tangkudung, James. Kepelatihan Olahraga "Pembinaan Prestasi Olahraga". Jakarta: Cerdas jaya, 2008 
[22] Uyanto, Stanislaus S. Pedoman Analisis Data dengan SPSS. Yogyakarta: Graha ilmu, 2006.

[23] Verducci, Frank M. Measurement Concepts in Physical education. St.Louis Missouri: Mosby Company, 1980.

[24] Widiastuti. Tes dan Pengukuran Olahraga. Jakarta: Rajagrafindo Persada, 2015.

[25] Wulan. Pengaruh Gaya mengajar dengan Motivasi Terhadap Hasil Belajar Driblle Bola Basket di SMK
Karya Wijaya Kusuma Jakarta. Jakarta, 2014.

\section{Profil Penulis}

Nama YoghaZulvian Iskandar lahir di Karawang, 26 November 1990, Pendidikan S1 Universitas Pendidikan Indonesia, Prodi Pendidikan Jasmani Kesehatan dan Rekreasi (PJKR) Lulus tahun 2014, S2 Universitas Negeri Jakarta, Prodi Pendidikan OlahragaRekreasi lulus tahun 2016, dan sekrangMengajar di Kampus STIT RakeyanSantangKarawang. 